\title{
The Imagination in Kant and Fichte
}

\section{Virginia López-Domínguez}

\section{(2) OpenEdition}

\section{Journals}

Electronic version

URL: http://journals.openedition.org/ref/952

ISSN: 2258-014X

Publisher

EuroPhilosophie Editions

\section{Electronic reference}

Virginia López-Domínguez, "The Imagination in Kant and Fichte », Revista de Estud(i)os sobre Fichte [Online], 17 | 2018, Online since 01 December 2018, connection on 08 September 2020. URL : http:// journals.openedition.org/ref/952

This text was automatically generated on 8 September 2020 .

(c) EuroPhilosophie 


\title{
The Imagination in Kant and Fichte
}

\author{
Virginia López-Domínguez
}

1 Traditionally, imagination has been dismissed or devalued by philosophy. For centuries, it was considered a minor and secondary function in the constitution of our worldview. And this holds true for both its reproductive and productive aspects.

Plato first introduced it as an ability to reflect images (eikona), to create mere imitations of the tangible, of that which for him was already a copy of the ideas and, for that reason, was excluded from the realm of knowledge ${ }^{1}$. This negative view lasted right up to rationalism, where the theory prevailed that the image is - as Sartre said in The Imagination - a thing in our consciousness, a dead product, the result of complete passivity. In fact, Descartes, as well as Leibniz and Spinoza, considered the imagination as a derivative function, which degrades the truth by presenting it in a faded or confused way, compared to the clarity and distinction, characteristic of innate ideas. It is that erratic character which depends on the attachment of the imaginary to the bodies, that darkness that prevents this faculty to give clear account of the real and achieve the subtlety and perfection of true knowledge, but that does not mean that their products are false in themselves. It is rather the weakness of the will, which exceeds itself in judging and attributes to the imagined a status that does not correspond to it, refusing to admit that it is neither a perception nor can it be raised to the level of conceptual thought ${ }^{2}$.

3 In the second case, that of the creation of new images, the imagination again did not acquire a good reputation, although it was generally never considered a completely new production but as a different ordering of previously experienced data. It was thought to build phantasmata, operating on the fringes of reality and producing a fantastic and illusory vision, contrary to the truth or, at least, unconcerned by it. Thus the opinion of the inefficacy and irrelevance of the imagination for science and for the transformation of the world was consolidated, tuning into a valid instrument only for the construction of utopias of artists and poets.

4 The view of the imagination changed radically after Kant, because with him, it became a fundamental active faculty in the process of knowledge. At this point, Kant continued the work of empiricism, but from a critical perspective. On the one hand, he followed 
Locke and Hume in their opposition to the theory of innate ideas and rejected the epistemic validity of those concepts whose origin does not refer to experience, but he acknowledged that data of perception are meaningless if they are not organized by successive synthesis, which filter and subsume the matter of knowledge under the pure subjective forms of sensibility and understanding respectively. For Kant, knowledge begins with experience while for Hume, everything originates in it. Ideas, at least in their simplest elements, are copies of an effective sensible impression. The imagination associates them actively and freely, that is, shapes our reality. While memory repeats impressions, preserving to some degree their original strength and vivacity, the imagination is free to modify the order of ideas. It can form complex mental content from the simple and even berak them down in order to reunite their elements according to its whim. It does so, however, following certain rules of association, which arise from qualities that lie in the ideas themselves, i.e. that the imagination gives a certain universality to their associations ${ }^{3}$, although it is a relative universality, because its norms guide, and even create habits of association, but are not imposed.

In contrast to Hume, Kant incorporated the rules of the imagination into the constitution of knowledge and granted them a universal and necessary value, provided that they remain under the subordination of the understanding, that is, provided that they are not "subjective and empirical ground of reproduction", which he called precisely "association of representations" (KrV, A 121). In this way, he managed to separate imagination from error and falsehood, but at the same time he gave imagination the ability to free itself from the intellect in order to become an authentic creative force, present both in aesthetic experience and in artistic production. He did this precisely to enhance its function apart from the understanding. With this he prepared the way for Fichte, Schelling and the Romantics, transforming it into an inventive activity, linked to genius and freedom, but at the same time, builder of our reality. Nevertheless, the old fear of the phantasmata, of the arbitrariness or the delirium, made Kant distrust the intervention of the imagination in the moral realm. And since he had admitted that practical reason is the key vault of the whole edifice of pure reason ( $\mathrm{KrV}$, Einleitung), he was unable to make it into the very center of all the activity of the subject, as his successors actually did. He simply stayed on the timid recognition that the ideas of reason are the "analogon" of a schema of sensibility (KrV, A 665 / B 693) and thus implicitly presenting the movement of the imagination as a model of the antinomic character of pure theoretical reason.

However, Kant was aware of the importance of the introduction of imagination in the Critique of Pure Reason, and in Lose Blätter (B 12) he acknowledged that it had been a decisive factor in the construction of Criticism, just as much as the substitution of the noumena by the transcendental concept of object. He also accepted the influence of Tetens' Psychology on this point, who argued that the rules of association implied an "inner and autonomous activity of the understanding", which combines the ideas and starts with experience but is not obtained from it through abstraction ${ }^{4}$. And perhaps to avoid such similarity, he insisted on distinguishing himself from him, attributing to this Psychology an empirical and subjective character, and defining his own analysis as transcendental and objective. But Tetens had also offered a more unitary model of the imagination, since for him it was not a separate faculty but an aspect of the faculty of representation, that performed three cognitive functions attributable to different levels of representation: perception, imagination and fancy formative power or Dichtkraft ${ }^{5}$. Somehow, this contributed to Kant considering imagination as a mediating 
faculty and trying to find, through it, the synthesis between the two sources of knowledge. In addition, Tetens had taken a step further by trying to explain the genesis of concepts unitarily. He had offered an epigenetic explanation of the concepts taking life sciences as a model, an explanation that Kant would record in the second edition of the Critique, just after reading and reviewing the first two parts of Herder's Ideas on the Philosophy of the History of Mankind ${ }^{6}$. These previous steps culminate in a holistic theory of human activity, which is precisely that of Fichte, although this does not mean that there was a direct and decisive influence of these authors on him. Rather, it seems that regarding the matter of imagination, Fichte takes these ideas from Kant himself and adapts them to his concern of building a system of freedom, taking into account Herder's suggestions on the need to incorporate the feeling to the basis of reason.

7 Although Kant is ambiguous with regard to the function of the imagination within the order of faculties, depending largely on whether it is artistic, productive (that is, transcendental) or reproductive imagination, in the Critique of Pure Reason prevails what Beck called the theory of radical diversity of the two sources of knowledge ${ }^{7}$. There are two separate, independent and irreducible modules or cognitive systems. On the one hand, there is sensibility, a totally passive faculty, capable of receiving representations through the pure forms of space and time. On the other hand, there is understanding, a spontaneous faculty, which enables to know such representations by actively ordering the data using categories in order to properly conform the object ( $\mathrm{KrV}, \mathrm{A} 85$ / B 118). The double origin of knowledge has repercussions on its products and thus the intuitions and concepts are completely opposite, since the former collect sensory data and offer the multiplicity and the individual, while the latter are intellectual, universal and encompass what is multiple in one unit. By being completely heterogeneous, categories can not be directly applied to the phenomenon; they require a mediator faculty - active and spontaneous - which is both sensible and intellectual (nonempirical) and manages to bring together the given multiplicity and unify it (A 137 / B 176). This is done through the transcendental scheme, which is not a fixed product, an "image-thing", but a rule, a procedure, by which the mind "draws" intermediate representations that serve to apply pure concepts to empirical intuitions. The transcendental scheme effects a sensitization, that is to say that it makes a temporalization of the categories, since time is the general form of sensibility. In this sense, imagination acts as "a blind function of the soul" (A 78 / B 103). It is not only that we are not usually aware of its functioning but also that we cannot anticipate what its final product will be in each of its interventions, because we do not know which of the categories will be used in the synthesis, for the adoption of a certain perspective to judge reality is spontaneous and therefore a free choice.

8 Fichte is completely faithful to Kant's theory of transcendental imagination, but he presents it from a different conception of philosophy, which will allow him to expand, deepen, and make it the basic faculty of man. Critical philosophy had established the conditions of possibility of knowledge through an analysis by which it separated the distinct faculties at stake and deduced the cognitive functions from their results or products. For example, from the judgments he came to the categories of understanding. In explaining the whole of human knowledge, Kant had proceeded from its elements, and in this progression from one to another, he created a dichotomous and partial vision, in which each new phase was added to the previous (per appositionem) without arising from it as a necessary articulation (per intus susceptionem). This was the procedure used by Kant, although in the "Transcendental Doctrine of Method" he 
suggests another "architectural". Fichte, however, followed this suggestion. On the one hand, he wanted to build a system of philosophy and in the context of the age this meant starting from a single, first, unconditioned principle, and derive all reality from it. In this way, the transcendental method became genetic. Fichte took his principle, the last explanatory ground of the system, from the second Critique, from the Kantian idea that the key to the whole edifice of reason lies in practical reason. And so his starting point was the Thathandlung, the absolute action, without further conditions. This would give rise to a holistic vision, where the unity underlies the different human faculties, in a globalizing process led by the imagination, which creates new spheres of freedom, constructing all human activity, whether theoretical, practical, aesthetic or political.

9 In order to develop the imaginative process in Fichte, I have chosen the Wissenschaftslehre nova methodo, not because in this work there is something truly new in the evolution of his thought regarding this matter, but because, being a complete systematization of the entire period of Jena, he perfects and clarifies the exposition of the Grundlage der gesamten Wissenschaftslehre, introducing further clarifications; for example, the Einleitungen or the Grundlage des Naturrechts, in which Fichte assumes the criticisms and misinterpretations that his philosophical system has led to. As far as our subject matter is concerned, in this work the relation between imagination and freedom is better expressed, and to a great extent for this reason the imagination is shown more clearly as the basic faculty of the subject. Driven by the feelings that arise from the primary contact of the subject with the world, it operates by attempting the conjunction of opposing emotions, whereas the understanding (Verstand) is secondary and dependent on it, since it is passive and merely receives the imaginative process when it stops and sets at a certain point. This synthesis of opposing emotions is the expression on the most intimate and subjective level of the integration of the empirical with the intellectual intuition. In this way, Fichte avoids the hypostasis of the absolute I, characteristic of the Grundlage by showing that intellectual intuition is a process of the finite I in which an absolute instance immanent to him is revealed. Finally, in the Nova methodo it is seen more clearly how Fichte's approach to imagination points to the unity, integrity and totality of human activity. That is, to an organic conception of subjectivity that does not present the realization of the categorical imperative so much in the form of duty - as a struggle against inclinations and feelings, as in Kant - but in the form of coherence, of the law of restitution of the proper balance of homeostatic processes. This organic view of man and knowledge obeys that both the categories and the pure forms of sensibility, time and space, are not accepted merely as facts of consciousness for which a condition of possibility is sought, but are rather deduced from the dynamic itself of the imaginative process, a process that can only find its fullest sense when consummated in reality by assuming a material field of action, which is the human body (Leib) and which in this work is identified with the soul.

The beginning and foundation of all consciousness, and therefore of all reality, since there is no other reality for the subject than what he can understand and grasp, is freedom in the Nova methodo:

"die Freiheit ist sonach der erste Grund und die erste Bedingung alles Seyns und alles Bewusstseins". consciousness of freedom, its idea: 
"der Gedanke der Selbstständigkeit und Freiheit das höchste und erste ist" (MK, 15). explaining the irrationality on which consciousness is based, that, being separation limitation and finitude, presents an absolute, as an aspiration and even as a factum in the case of moral conscience. He will try to explain it based on finitude, opening it to the infinite, but without transcending the finite. This is why his next step in the Nova methodo, after presenting absolute freedom as a postulate, is to place himself on the plane of consciousness by avoiding the hypostasis of the absolute I and to admit that without self-consciousness, consciousness cannot be given or, in other words, that there can be no freedom without awareness of freedom:

"Das Bestimmte muss anschaubar sein, denn nur unter Bedingung seiner Anschaubarkeit ist Freiheit möglich, welche Bedingung des Bewusstseins ist" (MK 52).

This is the point at which effective freedom begins, which, given its close relationship with the imagination, can only be realized through trials, testing, through a maturity exercise.

Thus, the true starting point of philosophy is the very beginning of consciousness, with a pure and unconditioned activity of self-assertion that has no effect in the world, for in that case it would annihilate it without ever being able to distinguish itself from it. This activity projected into the infinite is defined as tendency or aspiration towards the absolute (Tendenz, Streben) and constitutes the very presence of the absolute in the finite subject. And precisely because of this finitude, the tendency ends up finding an obstacle in its path of expansion that forces it to return to itself and initiate a re-flexion - according to the terms of the Grundlage ${ }^{10}$. The encounter is felt as an impact (Anstoss ${ }^{11}$ ) that serves as an occasion for a centripetal activity of self-determination. It seems as if the very energy of the I was returned to it because it has been unable to carry it out, although this implies a resistance, registered by the I through a feeling of limitation. This gives him the guideline that there is something different from it, a Not-I, which it has not grasped directly - in situ, as it were, outside itself - but only through its own 
limits, through the effect that the Not-I has produced in him. Hence in the Grundlage, Fichte affirms that regarding the world we can only have faith (Glaube ${ }^{12}$ ).

The limitation is therefore offered subsequently as an inexplicable fact, as a factum beyond which one can not go, but that could not have arisen without the previous spontaneity of the I, thereby recognizing the logical-ontological priority of the affirmation over denial - of being over nothing. Freedom, then, has allowed its limitation, its linkage, its Gebundenheit, to become concrete, and it has not completely denied itself because of this, for there is always the possibility that the I does not want to admit the obstacle and recognize it as such. In fact, this is largely what happens, because, once the movement of contraction, of reflection of the I, is initiated, it is not completed until the disappearance of the subject; rather, the tendency, whilst absolute, replaces the activity until it finds yet another limit. And in that encounter the initial process occurs again, producing an oscillation (Schweben) of the activity between two points - one fixed and another mobile - an oscillation that Fichte calls "imagination" (Einbildungskraft). Those poles between which the imaginative activity moves are the absolute I, represented by the tendency, and the absolute Not-I, that it is not able to penetrate. At the extreme points of the oscillation opposite feelings of integrity and lack occur respectively, so that imagination, as already happened in Kant, actively builds synthesis of unity with plurality, of the intellectual with the sensitive. At the periphery, at the outer limit - as it might be called - arises a feeling of limitation, of activity that has been restrained or impeded. Fichte calls this a "feeling" (Gefühl), in a provisional and in a loose sense, identifying it, as he had already done in the Grundlage, with what in Kant was the moment of the affection, the sensation ${ }^{13}$. In the center or the inner limit, there is a feeling of fullness, doubtless very vague, for at this point there is not really an externalization of the activity:

"Im Gefühl kommt das ganze unzertheilte Ich vor; sehen können wir das Ich nicht, aber fühlen" (MK, 78).

19 In spite of its imprecision, it is necessary to admit this purely subjective or ideal moment because in truth it is a certain emotion. It is even the most certain of all, since without it the restitution of the tendency after its limitation could not be explained. It is a feeling of affirmation of one's own being or of affirmation in life, an expression that will characterize the Fichte of the Berlin stage, but which is already suggested in the Nova methodo, since the imagination is defined as movement, as deed (That) or liveliness (Lebendigkeit) (MK, 202). Consequently, we must assume that its foundation is the Thathandlung, life, meaning not the biological life, but the spiritual one, which will end up expressing itself in the human, concretizing into the biological and seeking consciousness. Without this feeling of rooting in being and life, the I would let itself die after encountering the first obstacle of its performance.

In any case, the feelings bring to the subject a fact which he cannot doubt, for it is always the I that feels itself:

"Ich fühle nicht etwas, sonder ich fühle mich" (MK, 78).

However, to become an agent in the realm of knowledge, the feeling must be accompanied by an intuition. Already in the Grundlage, Fichte had recognized it by paraphrasing Kant: "intuition sees - he said then - but it is empty, the feeling is related to reality but it is blind" 14 .

And so, the oscillatory game of imagination combines - as Fichte puts it - four pieces (Stïcke) MK, 87: the feeling of limitation, the feeling of aspiration, the intuition of the 
determined object and the intuition of the ideal. Two feelings and two intuitions: a finite intuition, limited in some respect and variable in each moment, which is the sensible intuition, and an intuition of the absolute and infinite, the intellectual intuition, which is the fixed and immovable pole without which the consciousness would be lost trying to find support for its construction.

In this movement of reception and comprehension of data by subsumption of the plurality to the unity, the I is tense and distended as in a movement of systole and diastole ${ }^{15}$, by which it extends its activity and contracts it by admitting the cuts occurring in it. It is for this reason that Fichte describes the imaginative function as pulling lines (Linienziehen) or as projecting (Entwerfen, MK 110, $201 \mathrm{n}$.; GNR, SW III, 58). What is outlined in each case are the oscillating, variable limits of the I and, by reference to them, the contours of the world are also drawn. As Kant had already proven in the "Refutation of Idealism", world and consciousness are always correlative; consciousness is in a sense the world and the world is consciousness. Or, in Fichte's words:

"Ich bin nicht ohne Welt, und meine Welt nicht ohne mich" (MK, 223).

As we have said, consciousness develops between limits that are impenetrable, so that the reality that it comprises is also limited. However, it cannot renounce absolute activity, which, although it is unrealizable, remains in consciousness as it did from the beginning, under the form of a now limited aspiration or tendency, which Fichte calls drive, impulse (Trieb). This energetic and dynamic aspect - which unquestionably reminds us of Freud, if we ignore the libidinal content of the Freudian drives - allows Fichte to explain the imagination as a unitary process that intervenes both theoretically and practically.

In the realm of praxis the oscillation does not stop at the obstacle. Undoubtedly, the I becomes aware of it, but tries to extend its activity beyond the limit by imagining a practical project (das Ideal), which, as in Sartre ${ }^{16}$, has a direct relation to the restriction that the I discovered in the affirmation of its activity, because the project is imagined in order to solve the shortcomings that the subject found in its action. Such an extension of the activity is always accompanied by feelings that help the I become aware of what is happening in it. Since for Fichte there is no feeling without action and vice versa, there is no action without feeling, for the latter is considered the internal, the purely subjective side of the activity:

“Kein Gefühl ohne Handeln, kein Handeln ohne Gefühl” (MK 138).

This process of projection of the subjective activity, insofar as it is impelled by an absolute tendency, is potentially infinite. For this reason, the I puts as its ultimate purpose the full subjectivation of the world, its unrestricted affirmation, the absolute I, and this is what Fichte calls "idea" (Idee) of the I. It is an idea for reason, which operates at every moment of the subject's realization of his aspiration, and which, like all ideas, is only an unrealizable goal for the finite I. In the first place, by the very structure of consciousness that does nothing but move between boundaries. Second, because of the insurmountable physical barrier that death imposes on the empirical subject.

27 In the realm of theory, however, the I stops its movement by accepting its limitation and fixing in a product the synthesis that it obtained at that moment. We will return to how this process is performed. For now it is worth emphasizing that imagination, insofar as it is directly related to freedom, achieves a wider productivity in the praxis, since it allows to modify the world according to a project of affirmation of the 
subjectivity that does not admit the confines that are imposed from outside and, consequently, denies the world in order to create a more harmonic environment.

Evidently, imagination is presented in the Doctrine of Science as pure dynamism of constitution, as a movement of synthesis between the infinite and the finite, between the ideal and the real, the intelligible and the sensible, unity and multiplicity, or ultimately between the I and the Not-I, thus collecting the etymological meaning of the German word Einbildungskraft, as a unifying force, which forms in unity. As in Kant, its main function is productive; it is to create projects and not imitations or reproductions (MK 53). Although in Fichte's case, it is a more radical constructivism, which allows him to define the I as an eye and not as a mirror that is limited to reflect reality (MK 54). This distinction between project and imitation is perfectly captured in the German language. The imagination is primarily the ability to elaborate Vorbilder, that is, types or models prior to the finished image, which guide its construction; not Nachbilder, mere images, which are the result of the process and therefore something fixed, sclerosed, a product in a sense already reified. That is why it is interesting to note the fact that in his book on the imagination Sartre affirms that the great error of philosophy has been the consideration of the image as an object or a thing ${ }^{17}$, forgetting the contribution of transcendental idealism, not only the contribution of Fichte, but also that of Kant. However, unlike Kant, Fichte's treatment of the imagination is primary, since his explanation is genetic (MK, 192) and ultimately goes back to the absolute spontaneity of the I. The unity of the principle has repercussions on the unity of the imaginative process, whose root is in the activity of a single drive, and thus Fichte can extend the use of the imagination from the theoretical to the practical, making it the basic faculty of man:

"Im Denken ist kein Fliessen, da ist lauter Stehen, bloss in der Einbildungskraft ist

die Basis alles Bewusstseins, soll das Bewusstsein dieses Fliessens sein". (MK 208 n.)

The centrality of the imagination in Fichte is reinforced by his deducing it from its very internal dynamics of the pure forms of knowing, something which does not occur in Kant, for in his works there is no genetic explanation of the pure intuitions of space and time nor of the categories.

30 As in the Grundlage, in the Nova methodo the categories are moments of the imaginative movement, of the unfolding and contraction of the subjective activity, which are fixed by the absolute spontaneity of the I (reason = Vernunft), becoming passive products, in concepts of an understanding that is only limited to accept the syntheses obtained ${ }^{18}$.

31 As far as time is concerned, the Grundlage offers suggestions for its deduction by asserting that it is the conflict of the imagination with itself what distorts the condition of the I to a temporary moment (SW I, 217). But it is in the Nova methodo, where a detailed exposition of this question appears in which the origin of time is again linked to the imaginative work:

"Jeder einzelne Moment eine Dauer hat, diese entsteht aus dem Schweben der Einbildungskraft zwischen Entgegegesetzten. Darin besteht die Einbildungskraft, dass ich unendliche theilbares fasse, erst in diesen Zusammenfassen ensteht der Moment" (MK 206).

One of the opposites to which Fichte refers in this passage is the intellectual intuition, which I had just characterized as timeless (MK 136), an intuition that reveals an I that, by its absolute presence, is perpetual activity: eternity. The other opposite is the Not-I, a set of the different limitations endured by the activity as plurality versus absolute 
subjective unity. To become intelligible, this chaotic set requires order, it must become, as Fichte says, a series, a sequence (MK 88). But at the same time, the multiple sensations of the I can only be related and ordered in a succession if there is a point of reference always identical to itself, which is precisely the intellectual intuition. Thus, time is defined as the form of the multiple of intuition (MK 130) or as mediator between the sensible or the intelligible (MK $136 \mathrm{n}$.) and, in turn, as the connection that we are forced to put to our representations (MK 192). This connection is neither arbitrary nor external to the I. It arises from the tension and distention of the activity in the imaginative process. By introducing the temporal relation, consciousness is constituted as such, it differs from that accumulation of mechanically associated data by referring the series to itself, by adjudicating succession as its product. Thus, time is a peculiarity of consciousness itself; it is the form that the I gives to itself when it is related to multiplicity. Moreover, time becomes the ontological structure of the finite subject, where the being of the I is transformed into a progression. When the I wants to assert itself over the world and it finds obstacles to its expansion, it is forced to look for alternative ways, to oscillate between different options, to disperse its affirmation, to decompress it - as Sartre would say ${ }^{19}$ - finally seeking its own reunification. The concept of the purpose is then sketched out and, by outlining this goal, the duration is also created, because, thanks to sensitive mediations, successive actions arise to achieve this goal, the means that are linked in time to their end (MK 206 n.). In other words - which undoubtedly remind Sartre again - the I has to be completed in its unity and is forced to exist in the diasporic form of temporality.

Moreover, it is interesting to note that the deduction of time has inevitably been linked to its negation, to eternity. And vice versa, eternity is only given in reference to time. If Fichte had not recognized that intuition brings us into contact with the eternal, with something outside of time, he would have explained the metaphysical with proper physical coordinates. But if he had not closely linked the eternal to the temporal through the productive imagination, he would have become dogmatic leading to a mystique of the absolute, in which the individual would be absorbed by the totality. It is thus possible to present this link as one more attempt to emphasize the critical nature of his philosophy and his will to deepen human finitude.

As for the deduction of space, no reference is found in the exposition of the Doctrine of Science of 1794-95. The first reference appears in paragraph V of the Grundlage des Naturrechts. The Nova methodo incorporates this deduction by completing the theory of the imagination. As in the case of time, the explanation goes back to the absolute activity of the I, to the freedom that, being limited, requires a sphere of action (MK 114), which necessarily has to be in the Not-I and, therefore, must be material. In the face of an obstacle, imagination is set in motion, which outlines the limits of the I, and in doing so creates space as a form of external intuition (MK 111). The parallelism between this phase and that of the genesis of time reveals that it is a single process, that of the derivation of multiplicity, considered from two different perspectives, and allows to affirm that for Fichte space is externalized time, alienated and reified outside the subject. Thus, objects external to the I are always given in space and, conversely, space is always bound to objects (MK 112). Finally, matter is presented by Fichte as a subjective synthesis between space and objects, making it clear that the sphere of deduced action is the corporeal world (die Körperwelt, MK 112 n.). Now, the space between the different corporeal objects is relative and this could not arise if there were 
no fixed point from which to organize it, just as it is impossible to create a temporal sequence if no reference is made to an inalterable axis and outside time as represented by intellectual intuition. In this way, it is also necessary to formulate an absolute space (MK 114), generated from an identical point that for each particular I is its own body (MK 124). Thus, in a similar way as was already done in the Grundlage des Naturrechts, also in the Nova methodo the deduction of space is associated with the deduction of the body as a system of sensibility - whose existence is noted by the subject - of what Fichte calls "original feeling" (Urgefühl, MK 139). At the same time, as in that work, the deduction of corporality leads to the deduction of other individuals (MK 150), of a material community, which serves as a sphere of manifestation of freedom, an indirect manifestation, that is always mediated by the immediate sphere of realization of the freedom of each one, which is the own body ${ }^{20}$. In this way, the body presents itself as an instrument of action in the world, but also - as Sartre said ${ }^{21}$ - as a way of adapting our consciousness to the world, with which it identifies itself. Precisely for this reason, for Fichte, the feeling that is at the basis of the uptake and assumption of our body is primary, it is the feeling that reveals our individuality, fundamentally our limitation, and therefore also our conscience. Hence, in its eagerness to accentuate the finite character of man, the Nova methodo culminates in the defense of the inseparability of body and spirit (MK 160), and the full identification of body and soul (MK 171) for it is a single reality, the same I perceived sensibly, but from two different strands: that of the external and that of the internal sense ${ }^{22}$.

By way of concluding this brief summary of the imaginative function, we can say that the greatest contribution of the Wissenschaftslehre nova methodo is to have placed the imagination at the center of all human activity, presenting it in a unitary way. Fichte prefers to refer to it using the geometric images that were dear to him in his youth, for example, almost at the end of the Nova methodo, he says that consciousness is a circle whose center is the intelligible, inseparable from the infinite, from which it extends, radiating through the imagination to the periphery, according to the necessary laws of thinking that connect the outer edge to its center allowing it to contain everything that is empirical and sensitive (MK 207). However, the process that is described is not so much a function of mathematical reason in its constructive power, but the creative and vital capacity of an organism in which homeostatic laws govern. On this matter Fichte, like most intellectuals of his time, has passed from the admiration of more geometrico of Spinoza to an organic and teleological vision ${ }^{23}$, which is precisely the one that is announced at the end of the Nova methodo and allows him to think nature as analogon of freedom. Fichte presents the human activity in a unitary and comprehensive way, as a dynamic process in which all the elements are put together, deepening the suggestion that Kant had made about the organic character of the reason ${ }^{24}$, complemented by the idea that there is an epigenetic theory, that allows to explain the synthesis of the categories from the transcendental apperception ${ }^{25}$.

Thus, at the beginning of the process is the undeveloped totality, that is, the tendency to the absolute, and, just as in an organism, that initial germ grows and matures in contact with the world in a game of action and reaction that ends up doing synthesis with that world in order to survive. In this game of exchange, the organism creates its own organs, which in this case, are the structures of the subject: time, space, concepts, practical projects, and so on. And the process of homeostasis itself creates them by maintaining an internal balance, which requires parallelism and complementarity of the opposing elements. Thus the feeling corresponds to intuition, intellectual intuition 
with the sensible, space with time, intuitions with concepts, categories arise in pairs, which find a synthesis in the third of each group, and the body with the soul.

Each one of the organs is important, necessary, because they all obey the end of the whole organism. Every moment is preserved without one displacing or replacing the other, even the most primitive, which are integrated by the higher moments. The final end is the realization of the effective freedom of the organism by intermingling with others, its full development in the world, the affirmation of its laws above the irrational. The creative capacity that realizes this process of subjectivation of the world, the synthesis, is the productive imagination. This subjectivation is only partial in knowledge, since the representations are determined by a feeling of necessity, whereas, in praxis, the subjectivation, besides being ideal, is real and, therefore, complete. Although it is limited by the particularity of individuals and the duration of their physical life, so that this process is posed as a task extended to the infinite, achievable gradually by humanity alone. And if the imagination can assume this basic and transforming function it is because it is a movement between two poles, a "between" that bridges lie on the gap that separates the intelligible and the sensible. Although the absolute can be the ultimate referent and the source that contains the mystery of life, the truth is that reality, consciousness and effective freedom, are in the interstice. Thus the Fichtean theory of imagination in the Wissenschaftslehre nova methodo shows us the absolute from the finite, a finitude that is consummated with the deduction of the body, a deduction that is realized through the imagination.

\section{NOTES}

1. Plato, The Republic, $510 \mathrm{n}$.

2. Descartes, R., Metaphysical Meditations VI (Tr. Morente: Madrid, Espasa Calpe, 2006, 121, 131, 175).

3. "according to itself given any time and place", Hume, D., Treatise I, I, Sec. IV, 10.

4. Tetens, J. N., Philosophische Versuche über die menschliche Natur und ihre Entwicklung, Riga, 1776, vol. I, 320 .

5. B 12, R 5635, E 67. Cfr. Beck, L. W., Early German Philosophy. Kant and his Predecessors. Cambridge Mass., the Belknap Press of Harvard University, 1969, 412-125 and Allison, H. E.: Kant's Transcendental Deduction: An Analytical-historial Commentary. Oxford, Oxford University Press, 2015, $153 \mathrm{n}$.

6. Kant, KrV, Parag. 27, B 166-168. In view of this text, Mensch argues that "Kant knew that his theory moved between Locke, Condillac and Bonnet". Cfr. Mensch, Jennifer, Kant's Organisation: Epigenesis and the Development of Critical Philosophy. Chicago, University Chicago Press, 2013. See also: $\mathrm{KrV}, 113 \mathrm{n}$.

7. Kant, KrV, A 50/B 74; Beck, op. cit., 268-269.

8. Fichte, J. G., Doctrine of Science nova methodo, 46, 51. The edition used here corresponds to the Krause Manuscript in the version of Erich Fuchs, appeared in Felix Meiner, Hamburg, 1982, from now on: MK. 
9. Fichte, ZEWL, SW I, 461 and WL, SW X, 114. Mme. De Stäel sums up Fichte's philosophy with the following formula: "Il faut comprendre l'incomprehensible comme tel" (De l'Allemagne IV, 253), which Fichte himself uses in a letter to Reinhold to define his thought. See Ruckerinnungen, Antworten und Fragen, par. 7 and 8, SW V, $341 \mathrm{n}$.

10. Fichte, GWL, SW I, see the "Deduction of representation".

11. GWL, SW I, 212, 228, among others.

12. GWL, SW I, 301 and 328.

13. MK, 68. See also GWL, SW I, $134 \mathrm{n}$. and ZEWL, SW I, 490.

14. SW I, 319. See also MK, 71, 79 n. and 87.

15. The expression is used by Novalis in Algemeines Brouillon to refer to the two movements of the divine life, which are expressed both within the subject and in nature. Novalis Werke (ed. Edward Wasmuth), Heidelberg, 1957, IV, 446.

16. Being and Nothingness, Part II, Cap. IV: "The for-itself and the being of the possible".

17. Sartre, J. P., The Imagination. Tr. Buenos Aires, Sudamericana, 1978, $22 \mathrm{n}$.

18. In this way, Fichte gathers the etymological meaning of the German word Verstand, as what remains, MK $32 \mathrm{n}$.

19. Being and Nothingness, Part II, Cap.II. "Ontology of temporality".

20. On this matter, see my article: "Die Idee des Leibes im Jenaer System", in Fichte Studien XVI (1999), 273-293.

21. Being and Nothingness, Part III, Cap. II, 1: "The body as being for-itself: facticity"

22. Fichte, WLnM, Halle Manuskript, GA IV, 2, 139.

23. Among these contemporaries we shall mention Herder, Goethe and Schelling. Fichte implicitly uses Herder's notion of organism, whose laws of behavior have not only served to explain evolution in nature but also in history. On this latter application, see, e.g., Ideas on the Philosophy of the History of Mankind, Part III, Chap. XV, 2 and 3. It is interesting to note that many of the principles used by Herder pass to Lamarck, although restricted to the purely biological sphere, as well as to H. Spencer, as he applies them in this case, also to society. It is also to be noted that the shift of theoretical interest from mathematics to life sciences already occurs in Leibniz, since, for him, medicine was the model science. This is reflected, of course, in his metaphysics and, in particular, in the idea of substance as a monad. Cf. Smith, Justin: Divine Machines. Leibniz and the Sciences of Life. Princeton, Princeton University Press, 2011.

24. KrV, BXXIII; BXXXVII n. and B 860 n./ A $832 \mathrm{n}$.

25. KrV, Par. 27, B 166-168. See Zöller, G., "Kant on the Generation of Metaphysical Knowledge", in Kant. Analysen-Probleme-Kritik. Würzbug, Könighausen \& Neumann, 1988, p. 85 n. and Moya, E., “Apriorismo, epigénesis y evolución” in Revista de Filosofía, 30, 2 (2005), 61-88.

\section{ABSTRACTS}

Traditionally, imagination has been dismissed or devalued by philosophy. For centuries, it was considered a minor and secondary function in the constitution of our worldview. And this holds true for both its reproductive and productive aspects. In this paper, it will be argued that the view of the imagination changed radically after Kant, because he considered imagination not only a fundamental active faculty in the process of knowledge but also an authentic creative force, present both in aesthetic experience and in artistic production. With this he prepared the 
way for Fichte, Schelling and the Romantics, transforming it into an inventive activity, linked to genius and freedom, but at the same time, builder of our reality. Fichte is completely faithful to Kant's theory of transcendental imagination, but, as it will be argued, he presents it from a different conception of philosophy, which will allow him to expand, deepen, and make it the basic faculty of man. Fichte took his principle, the last explanatory ground of the system, from the second Critique, from the Kantian idea that the key to the whole edifice of reason lies in practical reason. And so his starting point was the Thathandlung, the absolute action, without further conditions. This would give rise to a holistic vision, where the unity underlies the different human faculties, in a globalizing process led by the imagination, which creates new spheres of freedom, constructing all human activity, whether theoretical, practical, aesthetic or political.

INDEX

Keywords: Kant, Fichte, imagination

\section{AUTHOR}

\section{VIRGINIA LÓPEZ-DOMÍNGUEZ}

Madrid 